\title{
Preferred sources of help for mental health problems among Chilean adolescents: a descriptive study
}

\author{
Cecilia Olivari ${ }^{1,2 *}$, Carlos Mellado ${ }^{3}$, Rocío Casañas $^{4}$, Nancy Espinosa-Díaz $^{1}$, and Jaime Fuster-Villaseca ${ }^{5}$ \\ ${ }^{1}$ Departamento de Psicología, Universidad Católica del Maule, Talca, Chile; ${ }^{2}$ Centro de Investigación en Neuropsicología y Neurociencia Cognitiva, \\ Universidad Católica del Maule, Talca, Chile; ${ }^{3}$ Escuela de Psicología, Universidad Santo Tomás, Talca, Chile; ${ }^{4}$ Departamento de Investigación, \\ Asociación Centre Higiene Mental Les Corts, Grup CHM Salut Mental, Barcelona, Spain; ${ }^{5}$ Doctorado en Psicología, Universidad Católica del Maule, \\ Talca, Chile
}

\begin{abstract}
Background: A timely search for professional help regarding mental health issues in adolescents is critical in preventing severe disorders. However, adolescents generally tend not to seek help. This investigation aimed to study Chilean adolescents' willingness to seek help in mental health issues by identifying their preferred help-seeking sources. Methods: We conducted a cross-sectional-correlational study with 493 high school students between 14 and 19 years of age (mean \pm standard deviation $=16.28 \pm 1.29$ ). The instruments we used were the general help-seeking questionnaire (vignette version), adapted and validated in Chile, and a sociodemographic questionnaire. Results: Data showed that adolescents are more willing to seek help from informal rather than from formal sources. We identified no sex differences in terms of willingness to seek help from formal sources. However, males were more willing to seek help from informal sources. Conclusions: Similar to other cultures, Chilean adolescents are more willing to seek help from informal sources regarding mental health problems.
\end{abstract}

Key words: Help seeking. Mental health. Adolescents.

\section{Fuentes de ayuda preferidas para problemas de salud mental por adolescentes chilenos: estudio descriptivo}

\section{Resumen}

Introducción: La búsqueda de ayuda profesional oportuna para temas de salud mental en adolescentes es fundamental para evitar el desarrollo de trastornos más graves. No obstante, en general los adolescentes tienden a no solicitar ayuda. El objetivo de la presente investigación fue identificar las fuentes de ayuda para problemas de salud mental a las que los adolescentes chilenos están más dispuestos a dirigirse. Métodos: Estudio transversal-correlacional en el que participaron 493 estudiantes de secundaria de entre 14 y 19 años (media \pm desviación estándar $=16.28 \pm 1.29$ ). Los instrumentos aplicados fueron el Cuestionario General de Búsqueda de Ayuda (versión viñeta), adaptado y validado en Chile, y un cuestionario de datos sociodemográficos. Resultados: Los resultados obtenidos muestran que los adolescentes prefieren buscar ayuda en fuentes informales. No se identificaron diferencias por sexo en la disposición a buscar ayuda en fuentes formales, pero sí en la disposición a buscar ayuda en fuentes informales, pues los varones mostraron mayor disposición a hacerlo.

Date of reception: 22-06-2020

Date of acceptance: 03-09-2020

${ }^{*}$ Cecilia Olivari

DOI: 10.24875/BMHIM.20000182

E-mail: colivari@ucm.cl

1665-1146/@ 2020 Hospital Infantil de México Federicd (http://creativecommons.org/licenses/by-nc-nd/4.0/).

Available online: 08-06-2021

Bol Med Hosp Infant Mex. 2021;78(3):207-215 www.bmhim.com
} 
Conclusiones: En concordancia con la evidencia en otras culturas, los adolescentes chilenos presentan una mayor disposición a buscar ayuda para problemas de salud mental en fuentes informales.

Palabras clave: Conducta de búsqueda de ayuda. Salud mental. Adolescentes.

\section{Introduction}

Adolescence is a phase of life in which there is a greater vulnerability to initiate and develop risky behaviors such as substance abuse and mental health problems ${ }^{1,2}$. In this context, the World Health Organization reports that depression is the leading cause of morbidity and disability during adolescence ${ }^{3}$. Several epidemiological studies in Chile show a prevalence of depression between $6.1 \%$ and $8.3 \%$ in the adolescent population ${ }^{4,5}$. Regarding suicidal behavior, another investigation with school enrolled adolescents aged 13-18 years reported a lifetime prevalence of attempted suicide of $14.3 \%{ }^{5}$. Between 2009 and 2018 , the Ministry of Health recorded 1030 deaths associated with selfharm in the population between 8 and 18 years of age, which constituted the second leading cause of death in this age group in Chile ${ }^{6}$.

Regarding substance abuse, the latest national study in the general Chilean population estimated that $18.7 \%$ of adolescents between 12 and 18 years of age and $53.2 \%$ of young people between 19 and 25 consumed alcohol in the last month. Furthermore, a prevalence of risky alcohol consumption of $3.5 \%$ was identified for the 12-18 years old age group. In the previous year, the prevalence of marijuana use was $10.1 \%$ in adolescents aged $12-18$ years and $32.1 \%$ in young people aged 19-25 years?

Seeking timely professional help for mental health issues is considered a protective factor that can prevent the development of more severe disorders ${ }^{8,9}$. However, evidence indicates that adolescents tend not to seek professional help when faced with a mental health problem $^{10-14}$. Instead, adolescents tend to keep their problems to themselves; if they seek help, it would be preferably from peers or close adults ${ }^{11,15}$, most of whom have little or no knowledge of mental health. Consequently, they do not recognize that they are dealing with a specific problem or where to look for appropriate information about it ${ }^{16}$. Furthermore, it has been observed that adolescents with more emotional symptomatology and even suicidal thoughts are the least willing to seek help ${ }^{17-19}$. Among the main reasons that may influence the tendency to not seek help, even from mental health-care professionals, are the adolescents' need for autonomy ${ }^{20,21}$, stigma toward mental health issues ${ }^{22-24}$, fear of lack of confidentiality by the healthcare professional, and lack of mental health literacy ${ }^{25-27}$.

Help seeking is a complex process, with different stages, influenced by individual and social factors ${ }^{13,15}$. The process begins with being aware of the symptoms and accepting that one has a problem. Next, adolescents must be able to express and make themselves understandable to others, which will require the availability and accessibility of sources of help to which adolescents can reveal their needs ${ }^{13}$. Adolescents can obtain support from different formality sources ${ }^{13,28}$. Informal sources of help include casual relationships such as friends and family, and formal sources of help refer to people who have a recognized role and appropriate training in providing support and advice on health, such as health-care and mental health professionals $^{28}$. Seeking informal help has been considered a first step that precedes seeking and accessing professional help ${ }^{29}$.

In the present study, we sought to identify the sources of support for mental health problems that adolescents were most willing to approach. It is considered relevant since most of the studies on this subject have been conducted in English speaking populations, and only a few experiences are reported in other cultures ${ }^{11,30}$. Thus, inspired by the study of D'Avanzo et al. conducted in Italy, we studied the willingness to seek help in an adolescent Latino population. In contrast to the cited research, where the instrument used was the general help-seeking questionnaire in its original version, we studied the willingness to seek help with the general help-seeking questionnaire, vignette version, adapted in Chile ${ }^{31}$. Therefore, we explored different and specific mental health problems for which adolescents could indicate the degree to which they would select a particular source of help. As mental health issues are a dimension to be considered, the willingness to seek help is crucial in the help-seeking process ${ }^{28}$.

The present results may provide a better understanding of the help-seeking process in a previously unstudied sociocultural environment (Chilean adolescents). New evidence regarding the pattern of willingness to seek help may be useful for developing future interventions to promote timely help seeking. 


\section{Methods}

\section{Participants}

We conducted a non-experimental, cross-sectional, correlational study, including a universe of 17,736 high school adolescents in the commune of Talca, Chile. The sampling was non-probabilistic by convenience. The sample needed a minimum of 377 students to ensure $95 \%$ of confidence and $5 \%$ margin of sampling error (maximum variance of $50 \%$ ). The sample finally exceeded this minimum and consisted of 493 adolescents with an age range between 14 and 19 years (mean \pm standard deviation $=16.28 \pm 1.29$ ), of whom 238 were female (48.3\%). Moreover, 67.5\% corresponded to young individuals of a medium, medium-low, or low socioeconomic level from the commune's urban area. The remaining $32.5 \%$ corresponded to young individuals of medium-high, high, or very high socioeconomic status. Of the young people in the sample, $43.2 \%$ studied in municipal schools, $46.9 \%$ in private schools with state subsidies, and $9.9 \%$ in private schools.

\section{Procedure}

Twelve educational institutions were invited to participate in the study, of which seven accepted to participate. From November 2016 to April 2017, participants were recruited. After each institution authorized the study, we requested consent and assent forms. The questionnaires were applied collectively in the classroom. The ethics committee of the Universidad Católica del Maule approved this study.

\section{Instruments}

Besides a sociodemographic questionnaire that included age, sex, educational level, and educational institution, the general help-seeking questionnaire, vignette version GHSQ-V14, adapted in $\mathrm{Chile}^{31}$, was applied. This instrument assesses the likelihood of participants to seek help from specific proposed sources (partner, friends, parents, other family members, psychologist, physician, psychiatrist, and teacher or counselor) for seven different types of mental health problems (stress, anxiety, depression, suicidal ideation, substance abuse, psychosis, and physical illness). Regarding the questionnaire's reliability indexes (in this adapted version), alpha values ranging from 0.87 to 0.75 were obtained ${ }^{31}$. Each question shows a vignette that can be used independently, describing an adolescent with one mental health problem. Then, eight items with the proposed sources of help and a final item indicating that the adolescent would not seek help from anyone. In the present study, we included only stress, depression, suicidal ideation, and substance abuse. The following is an example vignette:

"Over the past two weeks, Juan has found it difficult to relax. He has also been feeling quite overwhelmed, 'nervous,' and intolerant. He has tended to overreact to things that happen."

Following each vignette, participants rate their intention to seek help for each source of support on a 7-point Likert scale, ranging from $1=$ very unlikely to $7=$ very likely.

\section{Results}

\section{Willingness to seek help from formal and informal sources}

We analyzed the willingness to seek help by adolescents according to different mental health problems. We performed a descriptive analysis of means and standard deviations of help seeking by type of problem (stress, depression, suicide, and substance abuse) and sources (informal and formal). Means and standard deviations were reported due to a normal-like distribution of variables. The minimum and maximum scores for each variable were 1 and 7 , respectively, where a low score means a low inclination to seek help from each source and a high score, an increased tendency to seek help.

Table 1 summarizes the results by type of problem and source of help seeking. It can be observed that, on average, adolescents prefer to approach their parents and friends among informal sources when they have issues with stress, depression, substance abuse, and suicidal ideation. Among formal sources, they prefer to turn to a psychologist for these problems.

Furthermore, extreme groups of adolescents were characterized according to their willingness to seek help from different help-seeking sources by calculating the percentage of participants who answered options 1 or 2 and 6 or 7 on the response scale for each type of problem. These options represented the lowest and highest intentions to seek help, respectively. Therefore, they were labeled as young people who were very likely or very unlikely to seek help.

The percentage of adolescents from the extreme groups (very likely and very unlikely) for the different sources of help, classified by stress, depression, suicide, and substance abuse problems is shown in 
Table 1. Means and standard deviations of help-seeking intentions for different problems and sources of help

\begin{tabular}{|c|c|c|c|c|c|c|c|c|c|c|c|c|}
\hline \multirow[t]{3}{*}{ Source of help } & \multicolumn{12}{|c|}{ Mental health issue } \\
\hline & \multicolumn{3}{|c|}{ Stress } & \multicolumn{3}{|c|}{ Substance abuse } & \multicolumn{3}{|c|}{ Depression } & \multicolumn{3}{|c|}{ Suicide } \\
\hline & n & $\mathbf{M}$ & SD & $\mathbf{n}$ & $\mathbf{M}$ & SD & n & M & SD & $\mathbf{n}$ & $\mathbf{M}$ & SD \\
\hline Informal sources & 485 & 4.39 & 1.25 & 492 & 4.37 & 1.44 & 488 & 4.43 & 1.38 & 487 & 4.23 & 1.67 \\
\hline Partner & 490 & 4.19 & 2.05 & 493 & 4.27 & 2.05 & 493 & 4.39 & 2.13 & 492 & 4.15 & 2.25 \\
\hline Friend & 492 & 4.64 & 1.93 & 492 & 4.73 & 1.97 & 492 & 4.58 & 1.95 & 492 & 4.52 & 2.14 \\
\hline Parent & 492 & 4.95 & 2.04 & 493 & 4.76 & 2.12 & 491 & 5.05 & 2.06 & 490 & 4.64 & 2.35 \\
\hline Other relatives & 488 & 3.77 & 2.11 & 493 & 3.72 & 2.18 & 491 & 3.68 & 2.09 & 491 & 3.59 & 2.29 \\
\hline Formal sources & 483 & 2.56 & 1.55 & 485 & 3.10 & 1.79 & 489 & 2.80 & 1.71 & 488 & 3.11 & 1.91 \\
\hline Psychologist & 491 & 2.94 & 2.02 & 490 & 3.55 & 2.17 & 491 & 3.31 & 2.20 & 493 & 3.78 & 2.36 \\
\hline Physician & 493 & 2.32 & 1.69 & 490 & 3.06 & 2.14 & 491 & 2.56 & 1.93 & 491 & 2.78 & 2.13 \\
\hline Psychiatrist & 486 & 2.40 & 1.89 & 492 & 3.16 & 2.18 & 492 & 2.63 & 2.02 & 492 & 3.23 & 2.33 \\
\hline Counselor & 490 & 2.60 & 1.84 & 491 & 2.65 & 1.97 & 493 & 2.68 & 1.94 & 491 & 2.68 & 2.01 \\
\hline
\end{tabular}

The total number of adolescents was 493. The missing data for each type of problem and source were calculated by subtracting the corresponding number of each cell from the total number of participants.

$\mathrm{n}$ : frequency; M: mean; SD: standard deviation.

Table 2. Help-seeking differences between informal and formal sources according to the type of mental health problem

\begin{tabular}{|l|c|c|c|c|}
\hline & $\begin{array}{l}\text { Informal } \\
\text { sources } \\
\text { M (SD) }\end{array}$ & $\begin{array}{c}\text { Formal } \\
\text { sources } \\
\text { M (SD) }\end{array}$ & t (DF) & p* $^{*}$ \\
\hline $\begin{array}{l}\text { Stress } \\
(n=476)\end{array}$ & $4.39(1.25)$ & $2.56(1.55)$ & $23.75(475)$ & $<0.001$ \\
\hline $\begin{array}{l}\text { Depression } \\
\text { (n=484) }\end{array}$ & $4.43(1.38)$ & $2.80(1.71)$ & $20.99(483)$ & $<0.001$ \\
\hline $\begin{array}{l}\text { Suicide } \\
\text { (n=482) }\end{array}$ & $4.23(1.67)$ & $3.11(1.91)$ & $13.47(481)$ & $<0.001$ \\
\hline $\begin{array}{l}\text { Substance } \\
\text { abuse } \\
\text { (n=484) }\end{array}$ & $4.37(1.44)$ & $3.10(1.79)$ & $15.67(483)$ & $<0.001$ \\
\hline
\end{tabular}

The total number of adolescents was 493. The missing data for each type of problem were calculated by subtracting the corresponding number of each cell from the total number of participants.

DF: degrees of freedom; M: mean; SD: standard deviation.

${ }^{*} p<0.05$ is considered statistically significant.

figures 1-4. A high percentage of the very likely group was observed in the "parents" category among the informal sources, meaning that these young people were very willing to seek help and would go to their parents in the first place. Among the formal sources, a high percentage of the very likely group was observed in the "psychologist" category. This pattern was similar for the four mental health issues consulted.

By comparison, a low percentage from the very unlikely group to seek help was observed in the "parents" category for stress and depression problems. These findings mean that adolescents who were unwilling to seek help showed less rejection toward their parents when they have stress and depression problems. Alternatively, for suicide and substance abuse problems, these adolescents showed less rejection toward their friends. Finally, in the very unlikely group, young people were less likely to reject the "psychologist" as a formal source of help for the problems surveyed.

\section{Differences in the willingness to seek help between informal and formal sources}

A Student's t-test for paired samples was performed to compare whether the adolescents sought help from formal or informal sources and identify the adolescents' preferred source of help seeking (Table 2). Significant differences were observed between sources for the different types of mental health problems: on average, adolescents prefer to turn to informal sources for help when they have stress, depression, suicide, and substance abuse issues. 


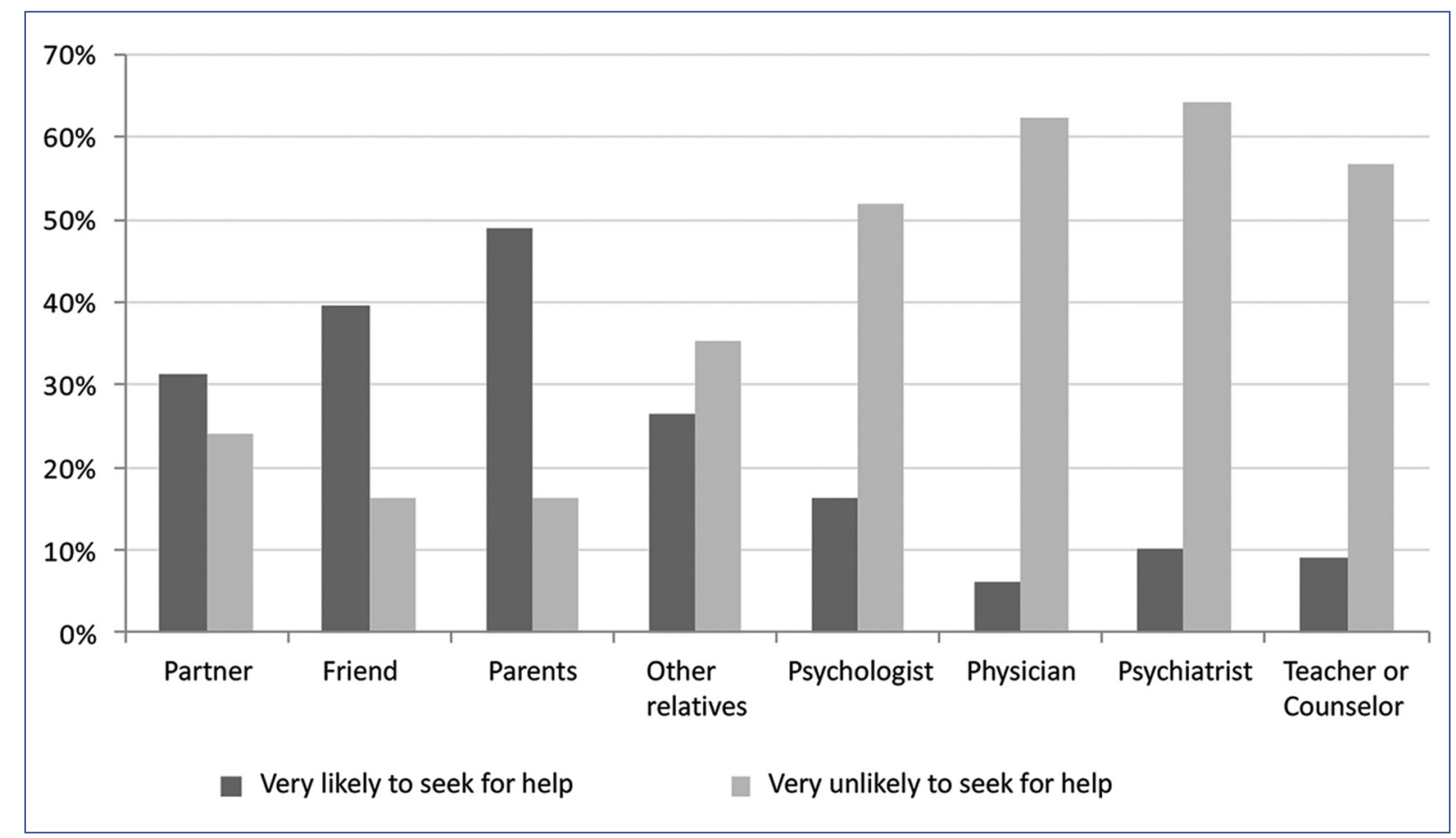

Figure 1. Percentage of young people who considered very likely or very unlikely to seek help for stress problems by type of source.

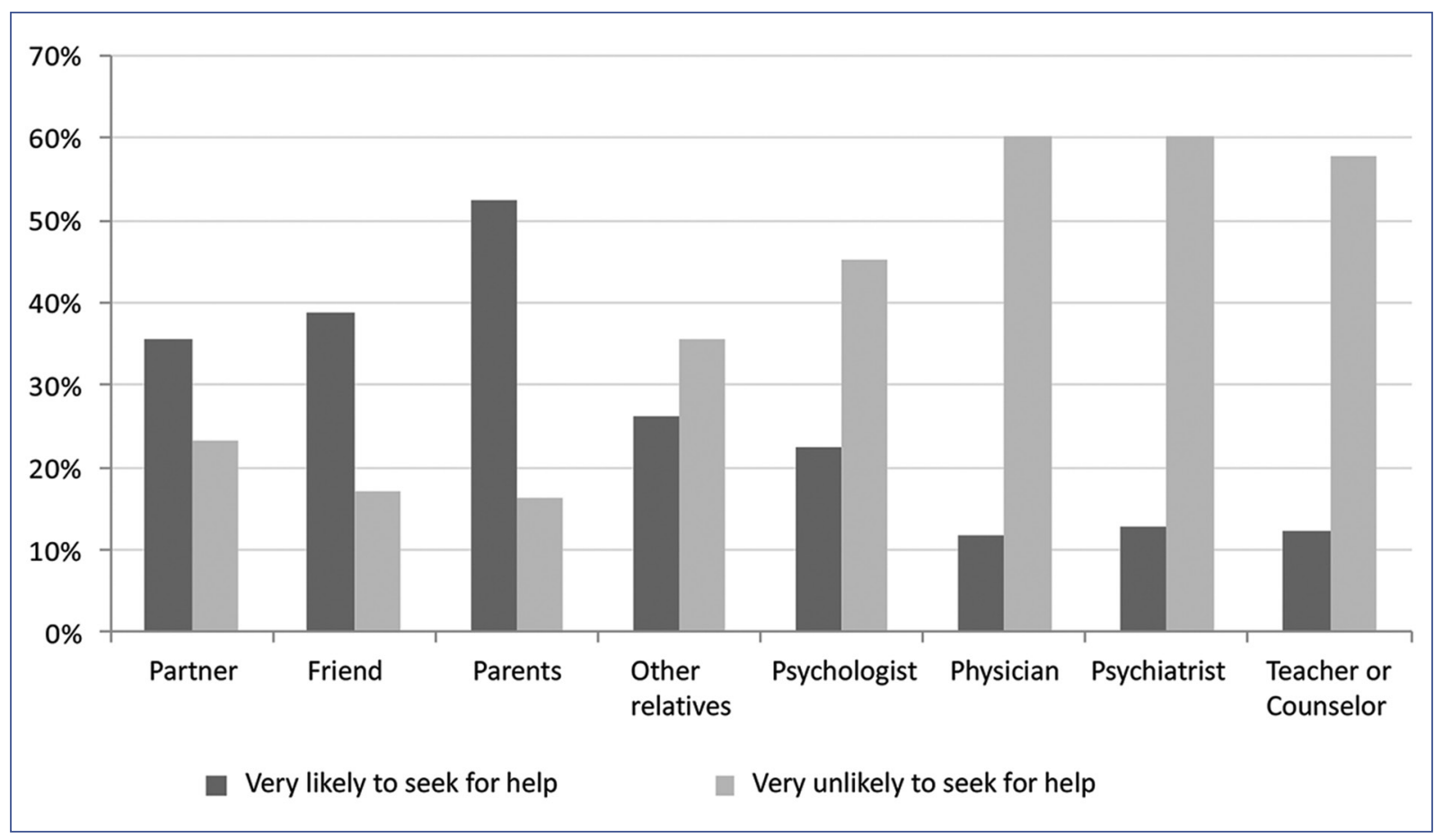

Figure 2. Percentage of young people who considered very likely or very unlikely to seek help for depression problems by type of source. 


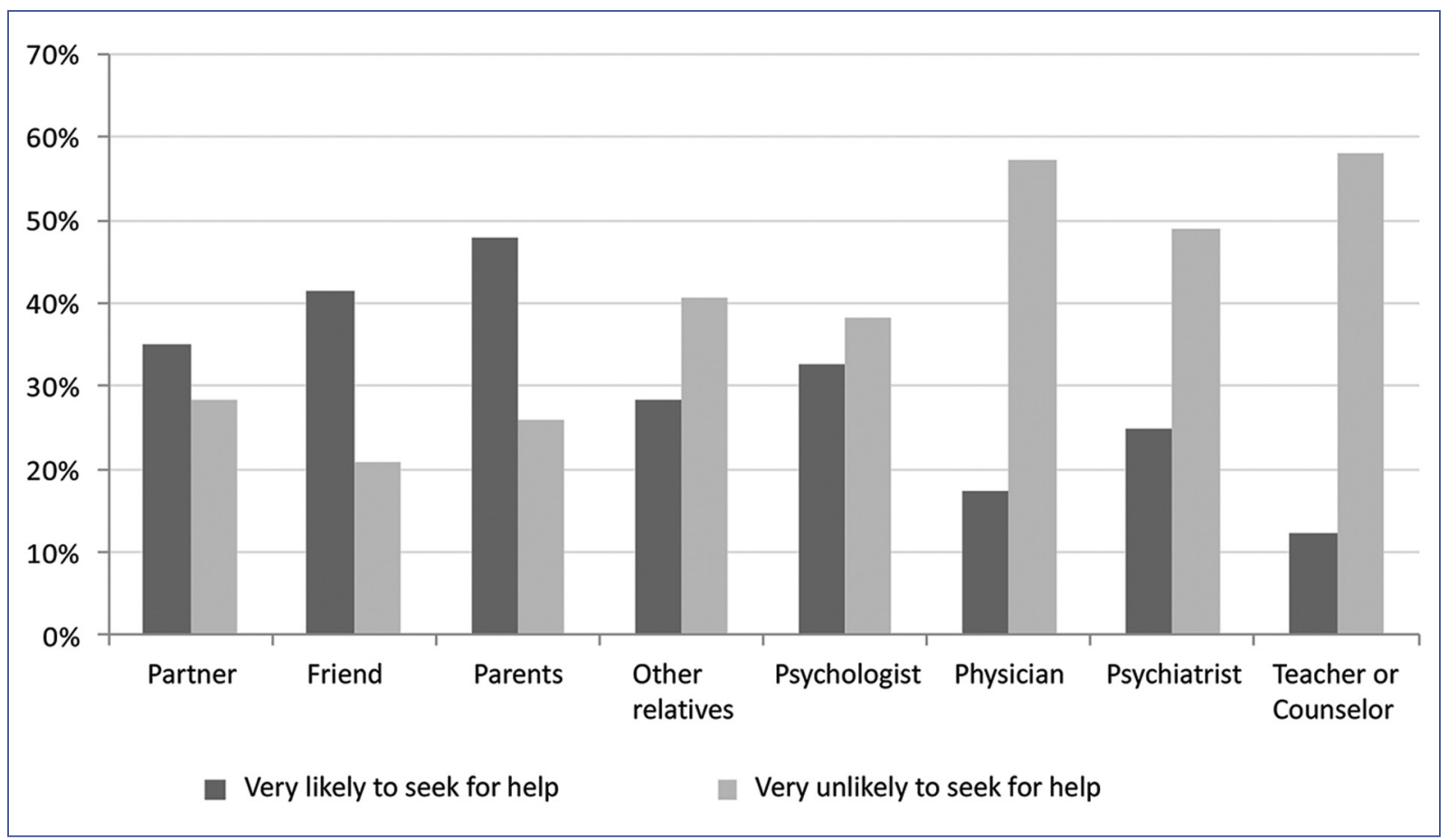

Figure 3. Percentage of young people who considered very likely or very unlikely to seek help for suicide problems by type of source.

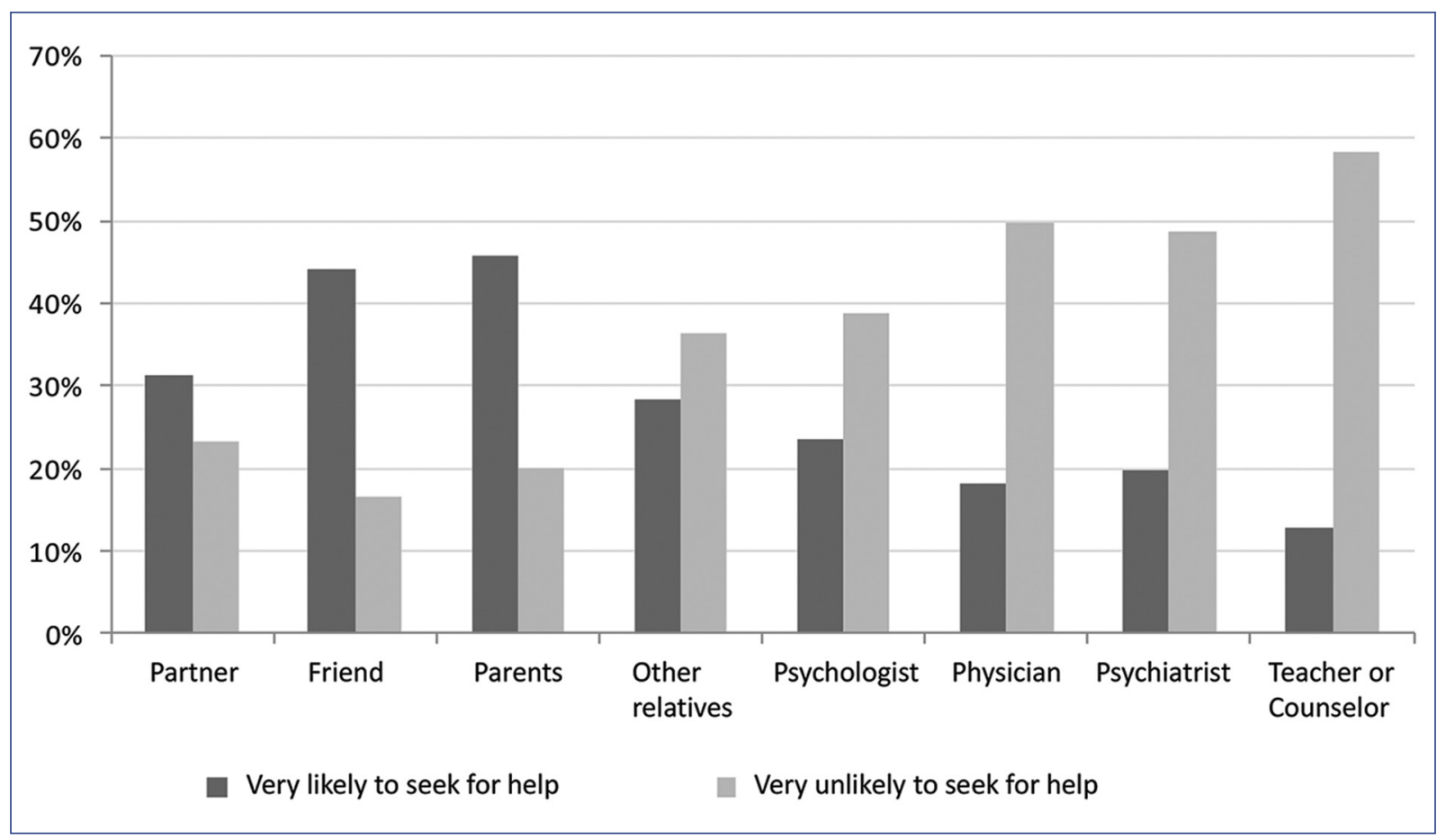

Figure 4. Percentage of young people who considered very likely or very unlikely to seek help for substance abuse problems by type of source. 
Table 3. Differences in help-seeking intentions by sex

\begin{tabular}{|l|l|c|c|c|c|}
\hline Type of problem & Source of help seeking & Male $(\mathbf{n}=\mathbf{2 3 2}) \mathbf{M}(\mathbf{S D})$ & Female $(\mathbf{n}=\mathbf{2 2 0}) \mathbf{M}(\mathbf{S D})$ & $\mathbf{t}(\mathbf{D F}=\mathbf{4 5 0})$ & $\mathbf{\mathbf { p } ^ { * }}$ \\
\hline Stress & Informal & $4.52(1.21)$ & $4.25(1.31)$ & 2.26 & $\mathbf{0 . 0 2 4}$ \\
\hline & Formal & $2.50(1.54)$ & $2.61(1.58)$ & -0.73 & 0.461 \\
\hline Depression & Informal & $4.62(1.30)$ & $4.20(1.45)$ & 3.24 & $\mathbf{0 . 0 0 1}$ \\
\hline & Formal & $2.78(1.71)$ & $2.77(1.72)$ & 0.78 & 0.938 \\
\hline Suicide & Informal & $4.54(1.54)$ & $3.86(1.75)$ & 4.40 & $<0.001$ \\
\hline & Formal & $3.23(1.87)$ & $2.99(1.94)$ & 1.31 & 0.189 \\
\hline Substance abuse & Informal & $4.59(1.38)$ & $4.14(1.49)$ & 3.34 & $\mathbf{0 . 0 0 1}$ \\
\hline
\end{tabular}

The total number of adolescents was 493. The missing data for each type of problem were calculated by subtracting the number of males plus females from the total number of participants.

DF: degrees of freedom; M: mean; SD: standard deviation.

${ }^{*} p<0.05$ is considered statistically significant.

Table 4. Correlation matrix between the willingness to seek help according to the type of source of help and problem

\begin{tabular}{|c|c|c|c|c|c|c|c|c|}
\hline Type of problem & 1 & 2 & 3 & 4 & 5 & 6 & 7 & 8 \\
\hline $\begin{array}{l}\text { Informal sources } \\
\text { Stress } \\
\text { Depression } \\
\text { Suicide } \\
\text { Substance abuse }\end{array}$ & $\begin{array}{c}-\overline{-} \\
0.74^{* *} \\
0.54^{* *} \\
0.57^{* *}\end{array}$ & $\begin{array}{c}481 \\
- \\
0.63^{* *} \\
0.61^{* *}\end{array}$ & $\begin{array}{c}480 \\
484 \\
- \\
0.61^{* *}\end{array}$ & $\begin{array}{l}485 \\
489 \\
488 \\
-\end{array}$ & $\begin{array}{l}477 \\
480 \\
479 \\
484\end{array}$ & $\begin{array}{l}482 \\
486 \\
485 \\
490\end{array}$ & $\begin{array}{l}481 \\
485 \\
484 \\
489\end{array}$ & $\begin{array}{l}479 \\
482 \\
482 \\
486\end{array}$ \\
\hline $\begin{array}{l}\text { Formal sources } \\
\text { Stress } \\
\text { Depression } \\
\text { Suicide } \\
\text { Substance abuse }\end{array}$ & $\begin{array}{l}0.29^{* *} \\
0.27^{* *} \\
0.25^{* *} \\
0.28^{* *}\end{array}$ & $\begin{array}{l}0.35^{* *} \\
0.41^{* *} \\
0.38^{* *} \\
0.35^{* *}\end{array}$ & $\begin{array}{l}0.29^{* *} \\
0.34^{* *} \\
0.49^{* *} \\
0.40^{* *}\end{array}$ & $\begin{array}{l}0.26^{* *} \\
0.30^{* *} \\
0.35^{* *} \\
0.40^{* *}\end{array}$ & $\begin{array}{c}-\overline{-} \\
0.78^{* *} \\
0.65^{* *} \\
0.62^{* *}\end{array}$ & $\begin{array}{c}482 \\
- \\
0.75^{* *} \\
0.71^{* *}\end{array}$ & $\begin{array}{c}481 \\
486 \\
- \\
0.78^{* *}\end{array}$ & $\begin{array}{c}478 \\
484 \\
482 \\
-\end{array}$ \\
\hline
\end{tabular}

Above the diagonal, the number for each correlation. The total number of adolescents was 493 . The missing data for each type of problem were calculated by subtracting the corresponding number of each cell from the total number of participants. ${ }^{*} \mathrm{p}<0.05 ;{ }^{* *} \mathrm{p}<0.01$.

\section{Differences in help seeking by sex, age, and socioeconomic level}

A Student's t-test for the variable sex and correlation analysis for age and socioeconomic level (SES) variables were performed to identify differences in the willingness to seek help according to these sociodemographic variables.

Regarding differences in help seeking by sex, we observed that males seek help from informal sources more than females for problems related to stress, depression, suicide, and substance abuse (Table 3). No significant differences regarding sex were observed in seeking help from formal sources for none of the studied problems. Furthermore, no significant association was found between age, SES, and help seeking from formal or informal sources for these mental health problems.

\section{Characterization of adolescents with low willingness to seek help}

Adolescents who showed a low willingness to seek help were characterized, so we calculated the percentage of participants who answered options 6 or 7 in the item I would not seek help from anyone. These options represent the highest likelihood of not seeking help. Adolescents indicated that they are very likely not to seek help for stress (13.8\%), depression (13.4\%), suicide $(15.9 \%)$, and substance abuse (11.6\%).

To identify differences by sex, age, and SES in low willingness to seek help, we performed a Student's 
t-test for the sex variable and correlation analysis in the case of age and SES variables. On average, females reported a greater probability of not seeking help for stress-related problems (t $[489]=2.06 ; p=0.040$ ). For problems related to depression, suicide, and substance abuse, no significant differences were observed according to sex. Furthermore, no significant association was found between age or SES and the reported probability of not seeking help for stress, depression, suicide, and substance abuse problems.

\section{Relationship between willingness to seek help from formal and informal sources}

To establish whether the willingness to seek help from informal sources is related to seeking help from formal sources, we performed a Pearson correlation analysis considering the different types of problems surveyed. Table 4 shows a significant correlation of all the variables. The correlations between seeking help from informal sources for stress, depression, suicide, and substance abuse problems were all positive and high, as well as the correlations between seeking support from formal sources for each of these problems. Finally, the correlations between seeking help from informal sources and seeking help from formal sources were positive and moderate according to the different issues.

\section{Discussion}

The present research aimed to identify the sources of help for mental health problems that Chilean adolescents are most willing to turn to, considering both formal and informal sources.

Adolescents considered help seeking as an option when facing the mental health issues investigated. Consistent with international evidence, adolescents exhibited a greater willingness to seek informal than formal help ${ }^{11,14,15}$. On average, we found that Chilean adolescents first choice were their parents, followed by their friends as their favorite alternatives for support. These findings are consistent with most studies in similar populations, which identify these two options as the primary informal sources adolescents turn to; however, in some of these studies, friends were their first choice followed by their parents as the preferred source of help ${ }^{11,12}$. In contrast, other studies ${ }^{13}$ showed that younger adolescents tend to be more influenced by their parents, who are their preferred source of help, especially their mother. Consistent with previous scientific literature, these results should raise the need to promote mental health literacy for parents (and guardians) and adolescents themselves ${ }^{32,33}$.

Formal sources of help were less chosen than informal sources, with the psychologist being the preferred source. This observation is consistent with other studies that have identified this same source as the one selected by adolescents (over the psychiatrist or general practitioner $)^{11}$. Furthermore, we identified a higher level of preference for counselors or teachers than general practitioners and similar to the psychiatrist in some topics. This study points to high school teachers as potential sources of help to which Chilean adolescents would be willing to turn when faced with mental health concerns or problems. As similar results have already been observed in other studies ${ }^{34}$, we should focus on increasing teachers' knowledge of mental health issues and sensitizing them on their role in help seeking by adolescents with mental health problems in our setting.

Regarding sex, we found mixed results depending on whether adolescents sought formal or informal help. Concerning informal help seeking, males tended to seek more help than females. In contrast to other studies in which females were identified to have a greater willingness to seek help ${ }^{13,35}$, our findings showed that males tend to seek more informal help. However, regarding formal help seeking, no significant differences were observed between female and male adolescents. Furthermore, we identified no gender differences in seeking help from formal sources, which coincides with other studies ${ }^{11,12}$. Therefore, it should be considered that our analysis differentiated between formal and informal sources of help, which allows us to know more precisely the people to whom adolescents would prefer to turn to when faced with a given mental health problem.

One of the limitations of this study is the age range of the sample (14-19 years). Although it was a representative non-consulting sample of schoolchildren in the Maule region, Chile, it did not include the entire range that defines the adolescent stage. Therefore, it will be of interest to conduct further studies of the help-seeking pattern by broadening the sample's age range and consulting on specific mental health issues. Knowing the pattern of help seeking in the population studied is essential to identify the preferred sources that adolescents turn to, which can undoubtedly be relevant for developing interventions for these groups and favor more effective support for their needs. 


\section{Ethical disclosures}

Protection of human and animal subjects. The authors declare that no experiments were performed on humans or animals for this study.

Confidentiality of data. The authors declare that they have followed the protocols of their work center on patient data publication.

Right to privacy and informed consent. The authors have obtained the written informed consent of the patients or subjects mentioned in the article. The corresponding author has this document.

\section{Conflicts of interest}

The authors declare no conflicts of interest.

\section{Funding}

This research has been funded by the Fondo Nacional de Desarrollo Científico y Tecnológico of the Chilean Government, Proyecto Fondecyt N ${ }^{\circ} 11130473$, granted to the first author.

\section{References}

1. Jones PB. Adult mental health disorders and their age at onset. $\mathrm{Br} J$ Psychiatry Suppl. 2013;54:s5-10.

2. Lubman DI, Berridge BJ, Blee F, Jorm AF, Wilson CJ, Allen NB, et al. A school-based health promotion programme to increase help-seeking for substance use and mental health problems: study protocol for a randomised controlled trial. Trials. 2016:17:393.

3. World Health Organization. Health for the World's Adolescents: A Second Chance in the Second Decade. Geneva: World Health Organization 2014. Available from: https://www.who.int/maternal_child_adolescent/ documents/second-decade/en.

4. De la Barra F, Vicente B, Saldivia S, Melipillán R. Estudio de epidemiología psiquiátrica en niños y adolescentes en Chile. Estado actual. Rev Med Clin Condes. 2012;23:521-9.

5. Silva D, Valdivia M, Vicente B, Arévalo E, Dapelo R, Soto C. Intento de suicidio y factores de riesgo en una muestra de adolescentes escolarizados de Chile. Rev Psicopatol Psicol Clin. 2017;22:33-42.

6. Ministerio de Salud. Recomendaciones Para la Prevención de la Conducta Suicida en Establecimientos Educacionales. Desarrollo de Estrategias Preventivas Para Comunidades Escolares. Santiago: Ministerio de Salud; 2019. Available from: https://www.minsal.cl/wp-content uploads/2019/03/GUIA-PREVENCION-SUICIDIO-EN-ESTABLECIMIENTOS-EDUCACIONALES-web.pdf.

7. Observatorio Chileno de Drogas. Décimo Tercer Estudio Nacional De Drogas En Población General De Chile, 2018. Santiago: Ministerio de Salud; 2019. Available from: https://www.senda.gob.cl/wp-content/ uploads/2020/02/ENPEG-2018.pdf

8. Barker G, Olukoya A, Aggleton P. Young people, social support and help-seeking. Int J Adolesc Med Health. 2005;17:315-35.

9. Del Mauro JM, Jackson Williams D. Children and adolescents' attitudes toward seeking help from professional mental health providers. Int J Adv Couns. 2013;35:120-38

10. Carlisle J, Shickle D, Cork M, McDonagh A. Concerns over confidentiality may deter adolescents from consulting their doctors. A qualitative exploration. J Med Ethics. 2006;32:133-7.
11. D'Avanzo B, Barbato A, Erzegovesi S, Lampertico L, Rapisarda F, Valsecchi $L$. Formal and informal help-seeking for mental health problems. A survey of preferences of Italian students. Clin Pract Epidemiol Ment Health. 2012;8:47-51.

12. Leavey G, Rothi D, Paul R. Trust, autonomy and relationships: the help-seeking preferences of young people in secondary level schools in London (UK). J Adolesc. 2011;34:685-93.

13. Rickwood D, Deane FP, Wilson CJ, Ciarrochi J. Young people's help-seeking for mental health problems. Aust E-J Adv Ment Health. 2005;4:218-51.

14. Rughani J, Deane FP, Wilson CJ. Rural adolescents' help-seeking intentions for emotional problems: the influence of perceived benefits and stoicism. Aust J Rural Health. 2011;19:64-9.

15. Gulliver A, Griffiths KM, Christensen H. Perceived barriers and facilitators to mental health help-seeking in young people: a systematic review. BMC Psychiatry. 2010;10:113.

16. Johnco C, Salloum A, McBride NM, Cepeda SL, Guttfreund D, Novoa JC et al. Mental health literacy, treatment preferences, and barriers in Salvadorian parents. Int J Ment Health. 2019;48:139-64.

17. Wilson CJ. General psychological distress symptoms and help-avoidance in young Australians. Adv Ment Health. 2010;9:63-72.

18. Wilson CJ, Deane FP. Help-negation and suicidal ideation: the role of depression, anxiety and hopelessness. J Youth Adolesc. 2010;39:291-305.

19. Wilson CJ, Deane FP, Marshall KL, Dalley A. Adolescents' suicidal thinking and reluctance to consult general medical practitioners. J Youth Adolesc. 2010;39:343-56.

20. Vogel DL, Wester SR, Larson LM. Avoidance of counseling: psychological factors that inhibit seeking help. J Counsel Dev. 2007;85:410-22.

21. Wilson CJ, Deane FP. Brief report: Need for autonomy and other perceived barriers relating to adolescents' intentions to seek professional mental health care. J Adolesc 2012;35:233-7.

22. Clement S, Schauman O, Graham T, Maggioni F, Evans-Lacko S, Bez borodovs $\mathrm{N}$, et al. What is the impact of mental health-related stigma on help-seeking? A systematic review of quantitative and qualitative studies. Psychol Med. 2015;45:11-27.

23. Saporito JM, Ryan C, Teachman BA. Reducing stigma toward seeking mental health treatment among adolescents. Stigma Res Action. 2011;1:9-21.

24. Schnyder N, Panczak R, Groth N, Schultze-Lutter F. Association between mental health-related stigma and active help-seeking: systematic review and meta-analysis. Br J Psychiatry. 2017;210:261-8.

25. Kutcher S, Bagnell A, Wei Y. Mental health literacy in secondary schools: a Canadian approach. Child Adolesc Psychiatr Clin N Am. 2015;24:233-44.

26. Wei Y, McGrath PJ, Hayden J, Kutcher S. Mental health literacy measures evaluating knowledge, attitudes and help-seeking: a scoping review. BMC Psychiatry. 2015;15:291.

27. Yamasaki S, Ando S, Shimodera S, Endo K, Okazaki Y, Asukai N, et al. The recognition of mental illness, schizophrenia identification, and help-seeking from friends in late adolescence. PLoS One. 2016;11:e0151298.

28. Rickwood D, Thomas K, Bradford S. Help-seeking Measures in Menta Health: a Rapid Review. Glebe NSW: The Sax Institute; 2012. Available from: https://www.saxinstitute.org.au/wp-content/uploads/02_Help-seeking-measures-in-mental-health.pdf.

29. Rickwood DJ, Mazzer KR, Telford NR. Social influences on seeking help from mental health services, in-person and online, during adolescence and young adulthood. BMC Psychiatry. 2015;15:40.

30. Cakar FS, Savi S. An exploratory study of adolescent's help-seeking sources. Proc Soc Behav Sci. 2014;159:610-4.

31. Olivari C, Guzmán-González M. Validación del cuestionario general de búsqueda de ayuda para problemas de salud mental en adolescentes. Rev Chil Pediatr. 2017;88:324-31.

32. Hurley D, Allen MS, Swann C, Okely AD, Vella SA. The development, pilot, and process evaluation of a parent mental health literacy intervention through community sports clubs. J Child Fam Stud. 2018;27:2149-60.

33. Ratnayake P, Hyde C. Mental health literacy, help-seeking behaviour and wellbeing in young people: implications for practice. Educ Dev Psychol. 2019;36:1-6.

34. Venkataraman S, Patil R, Balasundaram $S$. The need for assessing mental health literacy among teachers: an overview. Int J Res Med Sci. 2019;7:3210-5.

35. Houle J, Chagnon F, Lafortune D, Labelle R, Paquette KB. Correlates of help-seeking behaviour in adolescents experiencing a recent negative life event. Can J Fam Youth. 2013;5:39-63. 